Razones por las cuales la lógica cuantificacional de primer grado debe ser exigida por universidades públicas de Lima-Perú en sus temarios de exámenes de admisión

\author{
Mora Ramírez, Rafael Félix \\ Razones por las cuales la lógica cuantificacional de primer grado debe ser exigida por universidades públicas de \\ Lima-Perú en sus temarios de exámenes de admisión \\ Revista Educación, vol. 44, núm. 1, 2020 \\ Universidad de Costa Rica, Costa Rica \\ Disponible en: http://www.redalyc.org/articulo.oa?id=44060092021 \\ DOI: https://doi.org/10.15517/revedu.v44i1.37555
}

Esta obra está bajo una Licencia Creative Commons Atribución-NoComercial-SinDerivar 3.0 Internacional. 


\title{
Razones por las cuales la lógica cuantificacional de primer grado debe ser exigida por universidades públicas de Lima-Perú en sus temarios de exámenes de admisión
}

\author{
Reasons Justifying the Need to Require First-order Quantificational Logic on Admissions Exams Preparation \\ Manuals for State Universities in Lima, Peru
}

Rafael Félix Mora Ramírez

Universidad Nacional Mayor de San Marcos, Perú

rafael.f.mora@hotmail.com

(iD http://orcid.org/0000-0002-6420-493X

\author{
DOI: https://doi.org/10.15517/revedu.v44i1.37555 \\ Redalyc: http://www.redalyc.org/articulo.oa?id=44060092021
}

Recepción: 15 Junio 2019

Aprobación: 05 Noviembre 2019

\section{Resumen:}

El siguiente trabajo pretende evaluar la lógica aristotélica que se viene exigiendo en los temarios para los exámenes de admisión de ocho de las once universidades de Lima-Perú. Para ello, se hará un estudio comparativo entre la lógica aristotélica y la lógica cuantificacional de primer grado mostrando las limitaciones de la primera frente a la segunda. Se ha tenido acceso a los temarios de las universidades nacionales del Callao, de Ingeniería, Federico Villareal, de Educación Enrique Guzmán y Valle, José Faustino Sánchez Carrión, Tecnológica de Lima Sur, de Cañete y la de Barranca. Se ha procedido a extraer los contenidos de lógica aristotélica los cuales se suelen enseñar en los manuales de las academias que preparan a los futuros ingresantes para mostrar lo contradictorios e inadecuados que resultan con la lógica cuantificacional de primer grado. El análisis cualitativo de datos respectivo se elabora a través de la revisión bibliográfica de los documentos. La parte investigativa de lógica de este trabajo se divide en 1 ) Lógica Aristotélica, 2) Lógica de Clases, 3) Lógica cuantificacional de primer grado, 4) Cuadro tradicional de oposición de Boecio, 5) Casos Especiales de Proposiciones, 6) Inferencias Inmediatas por Operación y 7) Silogismo categórico. Finalmente, se concluirá que la lógica cuantificacional de primer grado representa tal grado de avance en los estudios de lógica que debería formar parte del temario de exámenes de admisión de Lima-Perú. Además, se recomendará la necesidad de una investigación empírica para cubrir los vacíos que este trabajo presente.

Palabras ClaVe: Lógica aristotélica, Lógica cuantificacional de primer grado, Validez, Silogismo.

\begin{abstract}
:
This study the Aristotelian logic requirement included on the admissions exams in eight of the eleven state universities in Lima, Peru. A comparison of Aristotelian logic and quantificational first-degree logic revealed the shortcomings of the former versus the latter after analyzing the syllabi of the following state university departments: Engineering at the National University of Callao, Education at the Enrique Guzman y Valle National University and the José Faustino Sánchez Carrion University; and Technology at the National Technological University of South Lima, the National University of Cañete and the National University of Barranca. All content dealing with Aristotelian logic was extracted from the manual used by test preparation centers to teach prospective applicants. The objective was to determine contradictions and faults found in first-order quantificational logic questions. A qualitative analysis was performed through a literature review. Research for the logic in this study is divided into 1) Aristotelian Logic 2) Class Logic, 3) First-Order Quantifiable Logic, 4) Boethius Traditional Square of Opposition, 5) Special recommendations, 6) Immediate inferences based on operations and 7) Categorical Syllogisms. it is concluded that quantifiable first-order logic has progressed significantly within the study of logic, that it must be included within the areas to be studied within the Admissions exams for universities in Lima-Peru. There is a need for empirical research to fill any gaps found in this study.
\end{abstract}

KEYWORDS: Aristotelian logic, First-order quantificational logic, Validity, Syllogism.

\section{Estado DE LA CUESTIÓN}

Existen estudios previos sobre el temario del examen de admisión, pero no en relación con tema de la lógica. Así, por ejemplo, Garduño (2000) se enfoca en cómo los aspectos burocráticos terminan desplazando los aspectos pedagógicos del proceso educativo ante un examen de admisión. Además, Arévalo (2018) busca 
saber si los contenidos del examen de admisión de la Universidad Nacional de Ingeniería cumplen con las exigencias del perfil del estudiantado de la Facultad de Ingeniería Económica. Finalmente, Ponce y Escurra (2008) inquieren acerca del valor psicométrico del examen de admisión de la Universidad Nacional Mayor de San Marcos. Sin embargo, ninguno de estos trabajos contiene un análisis concentrado en la cuestión de la lógica.

Relacionado con la situación de la enseñanza de la lógica en el Perú se puede indicar lo siguiente. Francisco Miró Quesada Cantuarias asumió la cátedra del curso de Lógica en 1946 y publicó un texto sobre la materia en ese mismo año (Universidad Nacional Mayor de San Marcos [UNMSM], 2013). Hasta antes de esta fecha, no existía en América Latina algún libro introductorio de lógica. Es importante prestarle atención a este hecho porque, a decir de García y Palacios (1998), tendrá como resultado la inclusión del curso de lógica junto al de filosofía en los planes y programas curriculares de estudio para el estudiantado del quinto año de secundaria desde 1962. Este curso contenía temas relativos a lógica proposicional y lógica de clases y era enseñado tres horas por semana. Los textos que se usaban como base para dictar las clases de Filosofía y Lógica eran los de Augusto Salazar Bondy y Francisco Miró Quesada (1968) y Walter Peñaloza Ramella (1967); y estos eran los únicos que había.

Con el advenimiento de la Reforma Educativa de 1972, las horas de dictado se reducen de tres a tan solo una. Sin embargo, para 1998 el número de textos en relación con 1962 se incrementaría. En esta investigación se han encontrado los siguientes: Introducción a la Filosofía y Lógica de Julio Gutiérrez y Levi Saldaña (s.f.), Introducción a la Filosofía y Lógica Práctica de Carlos Bieberach (1971), Filosofía y Lógica de Luis Piscoya (1978), Filosofía y Lógica de Luis Bretel Bibus (s.f.), Lógica y Filosofía de Oscar García y Luis Gildomero Arista (1984), Filosofía y Lógica de Julián Nuñez (1984). Filosofía y Lógica de Pedro Blasco Cano y Pedro Chico Gonzales (s.f.), Filosofía y Lógica de Sixto García y Diógenes Rosales (1984).

Asimismo, en la actualidad, este curso de lógica si bien ya no tiene lugar en ciertos colegios se enseña de forma continua en algunos centros pre-universitarios y ello se refleja en dos textos que se han ubicado: Lógica/ Psicología de la Asociación Educativa Trilce (2005) y Compendio Académico de Psicología, Filosofía y Lógica de la Asociación Fondo de investigadores y editores (2007).

Nótese que la lógica no ha podido ser dictada de modo independiente. Siempre ha debido estar relacionada a la filosofía o a la psicología y, como veremos, incluso a la matemática, en especial, a la aritmética. De esto se deduce, que se concibe el curso de lógica como un complemento, es decir, como algo accidental y no esencial en sí mismo. Entonces, es menester aceptar que hay cierta indiferencia hacia la lógica que perdura incluso hasta hoy.

\section{Planteamiento del problema}

El principal objetivo que se pretende plantear en este trabajo es acerca de las diferencias formales entre la lógica aristotélica que se exige conocer para rendir un examen de admisión para ingresar a la universidad en Lima-Perú y la moderna lógica cuantificacional que rechaza gran parte de lo considerado válido por la silogística desarrollada por Aristóteles. Así, por ejemplo, al rechazar que la expresión Todos los médicos son profesionales no implica que Existen médicos (en lógica cuantificacional) desaparecen las relaciones (aceptables dentro de la lógica aristotélica) de contrarias, subcontrarias, subalternas y subalternantes del Cuadro tradicional de oposición de Boecio y tan solo sobreviven las relaciones contradictorias (Quesada, 2005).

Específicamente, se busca dar respuesta a esta pregunta: ¿Por qué motivos la lógica que se exige aprender para rendir los exámenes de admisión de las universidades de Lima-Perú debe ser la lógica cuantificacional de primer grado? La hipótesis principal es que la universidad debe estar acorde con los nuevos tiempos, lo cual significa incluir dentro de sus contenidos aquella lógica que ha probado ser muy productiva para la reflexión y el pensamiento críticos. Y esta no es otra que la lógica cuantificacional de primer grado. 
En este sentido, por ejemplo, la Universidad Nacional del Callao [UNAC] exige, en el apartado de Aritmética de su temario, que el postulante conozca lo siguiente: "Lógica proposicional. Proposiciones, conectivos lógicos. Tablas de verdad.

Teoría de conjuntos. Operaciones con conjuntos. Cuantifiadores [sic]. Problemas”, (UNAC, 2019, párr. 1).

En el prospecto de la Universidad Nacional de Ingeniería [UNI] se puede leer en el temario de Lógica lo siguiente: "Lógica III: La inferencia. Las reglas de inferencia. El silogismo categórico: términos, modos y figuras. Formas válidas del silogismo", (UNI, 2019, p. 34).

En el prospecto de la Universidad Nacional Federico Villareal [UNFV] se puede leer lo siguiente en el apartado de Lógica: "Proposiciones categóricas: Definición, estructura, características y tipos de proposiciones categóricas. Equivalencia de las formas atípicas a proposiciones categóricas típicas. Clases de inferencias inmediatas: conversión, obversión y oposición (Boecio)”, (UNFV, 2019, p. 11).

En el prospecto de la Universidad Nacional de Educación Enrique Guzmán y Valle [UNE] lo siguiente aparece en Matemática: "Lógica proposicional bivalente. Conectivos lógicos y proposiciones compuestas. Tautologías y contradicciones. Cuantificadores existencial y universal”, (UNE, 2019, p. 99).

En el prospecto de la Universidad Nacional José Faustino Sánchez Carrión [UNJFSC] lo siguiente aparece en Aritmética: "Lógica proposicional: Enunciados y proposiciones, conectivos lógicos, tablas de verdad. Proposiciones lógicas compuestas y tablas de verdad para proposiciones compuestas. Leyes de álgebra proposicional. Inferencias deductivas, cuantificadores", (UNJFSC, 2017, p. 6).

En el prospecto de la Universidad Nacional Tecnológica de Lima Sur [UNTELS] lo siguiente aparece en Filosofía y Lógica: "15. El silogismo categórico. Concepto. Estructura del silogismo categórico. Figuras del silogismo. Modos válidos del silogismo. Reglas del silogismo. Prueba de validez del silogismo mediante los diagramas de Ven. Falacias del silogismo categórico", (UNTELS, 2017, p. 19).

En el prospecto de la Universidad Nacional de Cañete [UNDC] lo siguiente aparece en Aritmética: "Lógica. Enunciados y proposiciones. Conectivos lógicos. Tabla de verdad. Tablas de verdad de proposiciones compuestas. Los argumentos y su estructura. Argumento deductivo e inductivo. Cuantificadores”, (UNDC, 2018, p. 3).

Finalmente, en el prospecto de la Universidad Nacional de Barranca [UNAB] lo siguiente aparece en Aritmética: "Relaciones lógica y conjuntos. Enunciados y proposiciones, conectivos lógicos, tablas de verdad de proposiciones compuestas, los argumentos: tipo y estructura, argumento deductivo e inductivo, noción y determinación de conjunto, relaciones y operaciones entre conjuntos", (UNAB, 2018, p. 2)

Algo de lo que es posible percatarse es que los contenidos de lógica han sido repartidos entre las áreas de matemática (aritmética) y de filosofía en los temarios de las distintas universidades públicas de Lima en la actualidad. Es interesante notar que ninguno de los referidos temarios menciona la materia de la lógica cuantificacional moderna. A lo mucho hay una breve alusión al asunto de los cuantificadores, pero solo conforme a la teoría de conjuntos. Más bien, lo que se expresa es un interés por motivar el aprendizaje de los diagramas de Venn, el manejo de los conjuntos y su relación con los cuantificadores, las formas válidas del silogismo, pero no se menciona si el método de los diagramas debe incluir o no el caso de la premisa existencial, ni bajo qué paradigma de lógica: la antigua o la moderna.

Objetivamente, ocurre que las academias y los centros pre-universitarios reproducen lo que se estipula en los prospectos determinados por las oficinas centrales de admisión. Pero hay que tener cuidado en estarle exigiendo a los y las estudiantes temas desfasados interesantes solo por motivos históricos (si las cosas van a ser así, entonces también se debería exigir en los exámenes de admisión a sumar con el ábaco y a multiplicar con números romanos). En suma, esta investigación plantea que en algunas universidades de Lima-Perú se exija no solo el aprendizaje de la lógica aristotélica sino también el de la lógica cuantificacional de primer grado porque se trata de una herramienta formal más precisa que la lógica de Aristóteles. Por todo lo anterior, se comenzará por exponer la lógica aristotélica para, poco a poco, ir criticando sus contenidos. 


\section{Metodología}

Para lograr cumplir el objetivo de esta investigación se ha usado la metodología de las investigaciones cualitativas, pues se interpreta con base en la lectura de las fuentes de la recopilación documentaria y mediante un estudio comparativo la situación de las exigencias de los temarios de exámenes de admisión de Lima-Perú en relación con la materia de lógica. Básicamente, se pretende sostener que dichas exigencias son limitaciones que no benefician en cuanto al filtrado de las habilidades lógicas del estudiantado que busca entrar en la universidad.

Además, este trabajo hace uso de métodos lógicos propios de la investigación en ciencias formales. Así, se utiliza la lógica de clases, la lógica de primer grado y la lógica aristotélica. Específicamente, se expone el análisis que ejecutan sobre los razonamientos silogísticos la lógica de primer grado y la lógica aristotélica y se procede a señalar sus diferencias. Una de ellas, por ejemplo, consiste en la apelación al método de la validez del silogismo por reglas aristotélicas por parte de la lógica de Aristóteles y la apelación al método de análisis lógico cuantificacional por parte de la lógica de primer grado.

\section{Resultados}

Se ha considerado que los resultados de esta investigación se dividan en las siguientes secciones: 1) Lógica Aristotélica, 2) Lógica de Clases, 3) Lógica de primer grado, 4) Cuadro tradicional de oposición de Boecio, 5) Casos Especiales de Proposiciones, 6) Inferencias Inmediatas por Operación y 7) Silogismo categórico.

Se debe mencionar que después de hacer la comparación debida entre lógica aristotélica y cuantificacional de primer grado, se valorará si la lógica aristotélica cumple con desarrollar de modo suficiente las habilidades de los ingresantes a las universidades. Al sostener que no es así, se propondrá a la lógica cuantificacional de primer grado en su lugar.

\subsection{Lógica Aristotélica}

La lógica aristotélica es también llamada lógica tradicional o silogística aristotélica. Fue desarrollada por Aristóteles con base en las llamadas proposiciones categóricas. No hay que confundirla con la lógica de clases la cual es aquella rama de la lógica que, para deducir, analiza las relaciones entre clases (o conjuntos) que hay en una proposición. La lógica de clases será un desarrollo posterior de esta lógica que se dará en el siglo XIX con Euler, Venn basado en Boole (Rosales, 1994).

\subsection{Lógica de clases}

Para entender el concepto de lógica de clases se consultará el texto de Diógenes Rosales. Escribe este filósofo:

La idea básica de los diagramas se debe al matemático Leonhard Euler (1707-1783) quien representó gráficamente las relaciones entre las clases o conjuntos. Euler usó la relación de inclusión para la universal afirmativa, la exclusión para la universal negativa, y la intersección para ambas particulares. En base a estas representaciones, el lógico inglés Jhon Venn (1834-1923) propuso representaciones gráficas de las proposiciones categóricas típicas A, E, I y O, gráficos que van a interpretar las ecuaciones booleanas, dado que Boole interpretó algebraicamente las proposiciones categóricas de la lógica tradicional. (Rosales, 1994, p. 165)

Es decir, George Boole planteó el álgebra de la lógica buscando convertir en ecuaciones las proposiciones categóricas. Sin embargo, el trabajo será completado años más tarde por Euler y Venn constituyendo la lógica de clases. Al igual que Rosales (1994), Kneale y Kneale (1980), sostienen algo semejante: 
En su Symbolic Logic de 1881, J. Venn -otro admirador de Boole- se serviría de diagramas a base de espacios intersectantes (esto es, de modelos topológicos) para ilustrar las relaciones entre clases o las condiciones de verdad de las proposiciones. Sus diagramas difieren de los de Euler en que en los mismos parten de representar todas las posibles combinaciones por medio de áreas diferentes para pasar luego a indicar, dentro de estas últimas, cuáles de esas combinaciones han de ser nulas -y cuáles no- para que sea posible hacer valer una proposición determinada. (...) (p. 389)

\subsubsection{Proposición categórica}

Es el enunciado que refleja una relación específica entre las categorías (o clases) sujeto y predicado. Solo existen cuatro proposiciones categóricas típicas (A, E, I y O). Asimismo, estas poseen cuatro componentes. Véase la Figura 1:

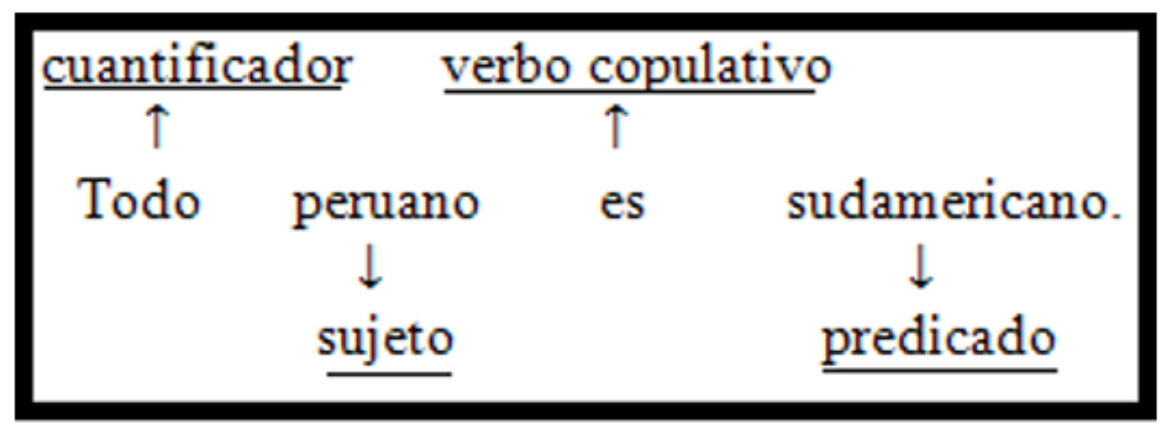

FIGURA 1

Elementos de una proposición categórica. Análisis de una proposición universal afirmativa. Fuente: Elaboración propia.

La expresión Todo peruano es sudamericano es una proposición categórica, puesto que refleja una relación entre sujeto (la clase de los peruanos) y predicado (la clase de los sudamericanos); a saber, que la primera clase está incluida totalmente en la segunda clase. Y, asimismo, posee, cuantificador, sujeto, verbo copulativo ser (en cualquier modo y tiempo) y predicado. Es decir, las proposiciones categóricas establecen una relación de inclusión o exclusión entre dos conjuntos de individuos: un sujeto y un predicado. A estos conjuntos de individuos se les llama categorías y, precisamente por eso, al tipo de proposiciones que se construye con base en ellas se les llama proposiciones categóricas.

\subsection{Lógica cuantificacional de primer grado}

También llamada lógica de primer orden o lógica predicativa. Es parte de la lógica clásica que, a diferencia de la lógica de grado cero (o proposicional), toma en cuenta no solo la estructura externa de las proposiciones sino también la estructura interna de las mismas al momento de efectuar el cálculo lógico. Por ello, en este contexto (tomando como base las variables proposicionales, los operadores lógicos y los signos auxiliares) se incorporan nuevas expresiones simbólicas: constantes individuales, variables individuales, constantes predicativas y cuantificadores. En relación con el uso de estos últimos se añaden, además, algunas reglas operativas. Se debe indicar que la silogística aristotélica es tan solo un trozo de la lógica de primer grado, específicamente se constituye como lógica de predicados unarios (o monádicos o no-relacionales) de primer grado. En ella no solo los adjetivos, sino también los nombres comunes y aun algunos verbos son asumidos como propiedades de objetos y procesos. Los cuantificadores $(\exists \mathrm{y} \forall)$, precisamente, son empleados para delimitar el ámbito de los individuos, toda vez que en este sector de la lógica se opera, básicamente, con proposiciones categóricas: proposiciones que exhiben términos como todos, algunos o sus respectivas negaciones (A, E, I y O). Por 
ello, se dice que la lógica de primer grado cuantifica sobre individuos. Los símbolos que introduce la lógica cuantificacional son:

1. Variables individuales, que representan individuos indeterminados.

2. Constantes individuales, que representan individuos determinados.

3. Constantes predicativas, que representan predicados determinados.

4. Cuantificadores, que hacen referencia a la totalidad o a una parte de los miembros de un conjunto. Son de dos tipos:

$(\forall$...): cuantificador universal $(\exists$...): cuantificador existencial

Los símbolos $\forall$ y $\exists$ se llaman cuantificadores. En el espacio vacío que le sigue dentro del paréntesis se colocan variables individuales: $(\forall \mathrm{x})$ y $(\exists \mathrm{x})$.

\subsubsection{Formalización de proposiciones categóricas}

a) Proposiciones universales afirmativas (A): Es aquella que contiene la expresión todos o alguna otra equivalente. Por ejemplo, la proposición Todos los gatos son animales se formaliza de la siguiente manera: $(\forall \mathrm{x})(\mathrm{Gx} \rightarrow \mathrm{Ax})$.

b) Proposiciones universales negativas (E): Es aquella en la que se niega la propiedad que se predica de cada uno de los individuos de un conjunto. Por ejemplo, Ningún león es pez se formaliza así: $(\forall \mathrm{x})(\mathrm{Lx} \rightarrow \sim \operatorname{Px})$.

c) Proposiciones existenciales afirmativas (I): También se denominan particulares. Son aquellas en las que aparece la expresión algunos u otras equivalentes. Por ejemplo, Algunos perros son domésticos, se simboliza así: $(\exists \mathrm{x})(\mathrm{Px} \wedge \mathrm{Dx})$.

d) Proposiciones existenciales negativas $(\mathrm{O})$ : Es aquella en la que se niega la propiedad que le fue asignada a ciertos individuos. Por ejemplo, Algunas aves no son gallinas se simboliza así: $(\exists x)(A x \wedge \sim G x)$.

Hay que anotar que esta lógica cuantificacional de primer grado permite transmitir información con mucha mayor concreción, es decir, con mayores detalles y especificaciones relevantes y esenciales para el entendimiento. Así por ejemplo, la siguiente expresión Todos los hombres son vertebrados. Juan no es vertebrado. Por ende, Juan no es hombre se puede simbolizar así:

$[(\forall \mathrm{x})(\mathrm{Hx} \rightarrow \mathrm{Vx}) \wedge \sim \mathrm{Vj}] \rightarrow \sim \mathrm{Hj}$.

Se puede notar que Juan se ha convertido en la constante individual j. Otro ejemplo, Algunos son políticos pero no todos son empresarios se puede representar así:

$(\exists \mathrm{x})(\mathrm{Px}) \wedge \sim(\forall \mathrm{x})(\mathrm{Ex})$.

Nótese que las variables predicativas $\mathrm{P}$ y E representar las propiedades de ser politico y ser empresario, respectivamente.

\subsection{Cuadro tradicional de oposición de Boecio}

Es un procedimiento mnemotécnico completado por Boecio en la época feudal. Se aplica para determinar la validez de inferencias que se establecen por relación de oposición. El cuadro de Boecio muestra las relaciones entre las cuatro formas típicas de las proposiciones categóricas. Véase la Figura 2: 


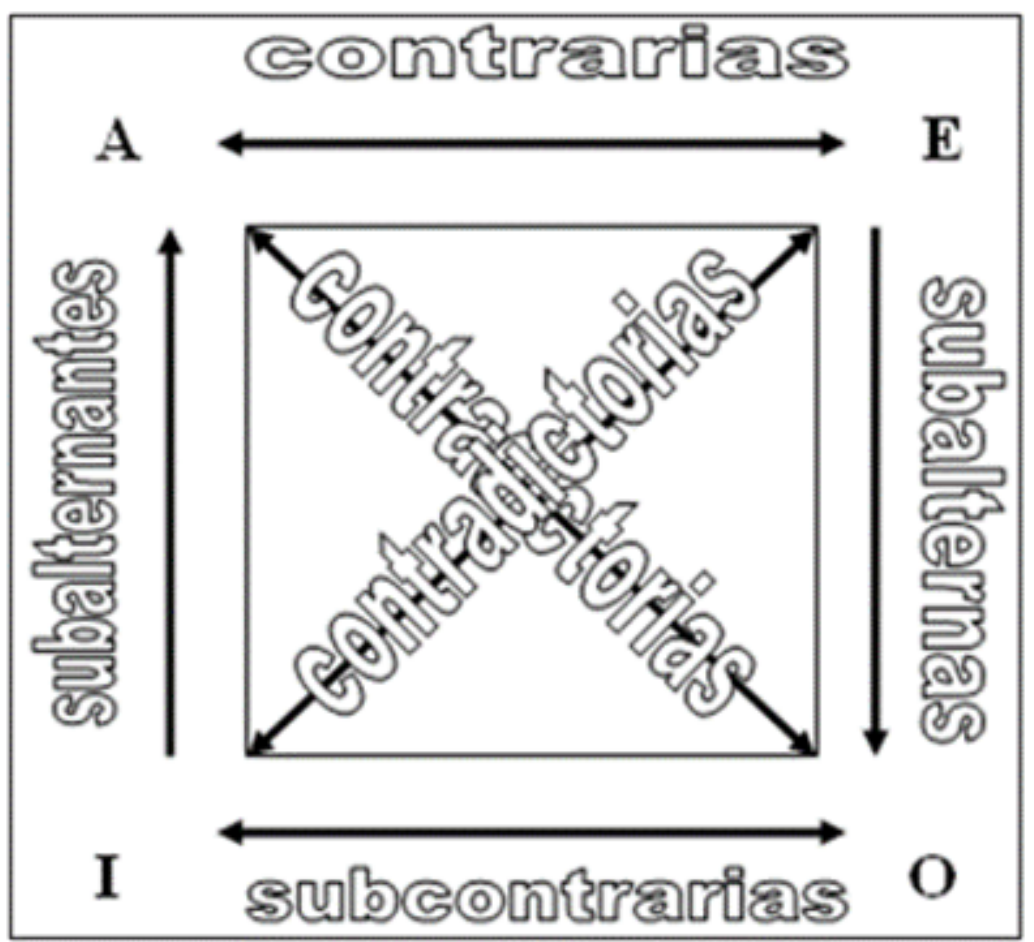

FIGURA 2

Cuadro de Boecio. Relaciones lógicas entre las cuatro proposiciones categóricas Fuente: Rosales (1994, p. 143).

\subsubsection{Equivalencias.}

Son aquellas fórmulas que establecen una relación de identidad entre una proposición y otra. Debido a que la equivalencia es una doble implicación, se puede asumir que el equivalente de una proposición es también su conclusión. Por ejemplo: Ningún libro es reciclable equivale a Es falso que algunos libros sean reciclables, pero también la segunda proposición es consecuencia lógica de la primera y viceversa.

a) Contradictorias. Las proposiciones de diferente cantidad y calidad son una la negación de la otra.

I. A $\leftrightarrow \sim$ O II. E $\leftrightarrow \sim$ I III. I $\leftrightarrow \sim$ E IV. O $\leftrightarrow \sim$ A

\subsubsection{Implicaciones.}

Son aquellas en las cuales de una premisa se sigue una conclusión. Por ejemplo: Ningún libro es reciclable. Por lo tanto, algunos libros no son reciclables. El asunto está en determinar si esta deducción es válida o no, y qué conclusión podría deducirse en caso que no fuera correcta. Para ello, se va a estudiar las relaciones restantes del cuadro de Boecio.

a) Subalternas. Se establecen entre proposiciones de igual calidad, pero diferente cantidad. Hay que decir que, como se verá más adelante, estas relaciones resultan inválidas bajo el análisis de la lógica de primer grado.

I. A $\rightarrow$ I II. $\mathrm{E} \rightarrow \mathrm{O}$

b) Contrarias. Se establecen entre proposiciones universales. En el esquema anterior de subalternas reemplácese los consecuentes $\mathrm{I}$ y $\mathrm{O}$ por sus equivalentes $\sim \mathrm{E}$ y $\sim \mathrm{A}$. Para que estas inferencias sean válidas, la conclusión debe ser negativa.

I. $\mathrm{A} \rightarrow \sim \mathrm{E}$ II. $\mathrm{E} \rightarrow \sim \mathrm{A}$ 
c) Subcontrarias. Se establecen entre proposiciones particulares. En el esquema de subalternas, reemplácese los antecedentes A y E por sus equivalentes $\sim \mathrm{O}$ y $\sim \mathrm{I}$. Para que estas inferencias sean válidas, la premisa debe estar negada.

I. $\sim \mathrm{O} \rightarrow$ I II. $\sim \mathrm{I} \rightarrow \mathrm{O}$

d) Subalternantes. Se establecen entre proposiciones de igual calidad, pero diferente cantidad. En el esquema de subalternas reemplácese antecedentes y consecuentes por sus equivalentes. Para que estas inferencias sean válidas deben negarse tanto la premisa como la conclusión.

I. $\sim \mathrm{O} \rightarrow \sim$ E II. $\sim \mathrm{I} \rightarrow \sim \mathrm{A}$

* Se debe señalar que, debido a que las contrarias, subcontrarias y subalternantes equivalen a las subalternas, serán inválidas puesto que las subalternas no son lógicamente válidas.

\subsubsection{El Cuadro de Boecio con base en la lógica cuantificacional}

Cuando el Cuadro de oposición de Boecio es sometido al análisis de la lógica moderna cuantificacional resulta drásticamente reducido. De acuerdo con la lógica cuantificacional, en dicho cuadro solo sobreviven las contradictorias, siendo tachadas por inválidas todas las demás relaciones. La Figura 3 presenta el cuadro de Boecio con la simbología moderna.

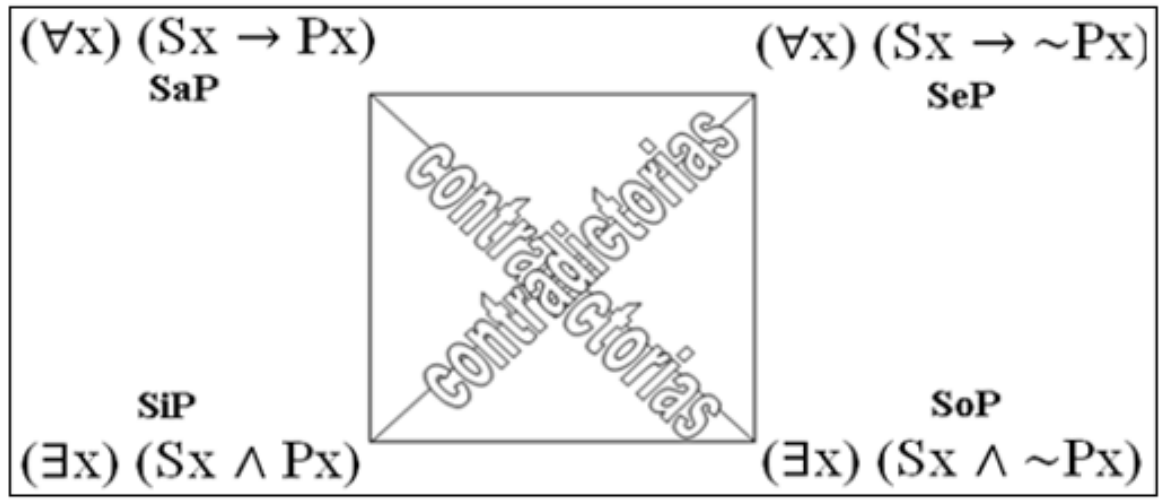

FIGURA 3.

Cuadro de Boecio y lógica de primer grado. Relaciones lógicas formalizadas.

Fuente: Copi (2001, p. 92).

La razón de esta reducción estriba en que Aristóteles -y los escolásticos generalmente- presuponían que toda proposición universal (como $\mathrm{SaP}$ (Todo $\mathrm{S}$ es $\mathrm{P}$ ) y $\mathrm{SeP}$ (Ningún $\mathrm{S}$ es $\mathrm{P}$ )) conllevaba la existencia de al menos una cosa que tuviera la propiedad $\mathrm{S}$. Tal suposición se llama el compromiso existencial. Ejemplos son Todo hombre es mortal ( $\mathrm{HaM}$ ) y Ningún hombre es una isla ( $\mathrm{HeI})$ : tanto $\mathrm{HaM}$ como HeI implican que hay al menos un hombre. En cambio, las correspondientes oraciones de la lógica cuantificacional $(\forall \mathrm{x})(\mathrm{Hx}$ $\rightarrow \mathrm{Mx})$ y $(\forall \mathrm{x})(\mathrm{Hx} \rightarrow \sim \mathrm{Ix})$, no tienen el compromiso existencial, es decir, no presuponen que haya cosas que tengan la propiedad $\mathrm{H}$. La diferencia es importante, pues Todo unicornio es cuadrúpedo sería verdadero en la transcripción $(\forall x)(U x \rightarrow C x)$ (pues solo dice que si hay un unicornio, entonces tiene cuatro piernas) y sería falso en la interpretación $\mathrm{UaC}$ (si implica que existe un unicornio realmente). Por eso, para crear una paridad entre las dos interpretaciones de la proposición universal, se debe expresar el compromiso existencial explícitamente:

SaP equivale lógicamente a $(\forall x)(S x \rightarrow P x) \wedge(\exists x) S x$

SeP equivale lógicamente a $(\forall x)(S x \rightarrow P x) \wedge(\exists x) S_{x}$ (Redmond, 1999)

Hay que señalar que $(\exists x)$ Sx significa que existe algo que tiene la propiedad de ser $S$. Y lo anterior quiere decir que tanto la $\mathrm{SaP}$ como la SeP suponen que hay algo que cumple la propiedad de ser $\mathrm{S}$. 
Entonces, las relaciones subalternas $\mathrm{A} \rightarrow \mathrm{I}$ y $\mathrm{E} \rightarrow \mathrm{O}$ ya no pueden ser válidas. Pues, a partir de $(\forall \mathrm{x})(\mathrm{S} \mathrm{x} \rightarrow$ $\operatorname{Px})$ no se puede deducir $(\exists x)(S x \wedge P x)$ a menos que se asuma que $(\exists x)$ Sx, pero ello alteraría el antecedente original de las relaciones subalternas. Lo mismo ocurre en $\mathrm{E} \rightarrow \mathrm{O}$. Y dado que las contrarias, las subcontrarias y las subalternantes resultan de reemplazar algún componente de las subalternas, también estas resultan incorrectas a la luz de la lógica cuantificacional. La razón de esto es que, para la lógica moderna, existe la cuantificación sobre el vacío y al afirmar que Todos los racistas son ignorantes no se dice que haya racistas, sino que en caso de haberlos serían ignorantes. (Manzano y Huertas, 2004). Es decir, en el caso del análisis cuantificacional el cuantificador universal carece de presuposiciones existenciales. $(\forall \mathrm{x})\left(\mathrm{P}_{\mathrm{x}} \rightarrow \mathrm{Qx}\right)$ no implica $(\exists \mathrm{x})$ Px; es más, la primera sentencia es verdadera si en el dominio no hay objetos a los que se aplique P. Por lo tanto, una cuantificación universal de un condicional es (vacuamente) verdadera cuando el predicado del antecedente no se aplica a ningún objeto del dominio, es decir, en lenguaje aristotélico, nada es sujeto de todo predicado. Por ejemplo, Todo centauro es orgánico sería verdadera. (Quesada, 2005)

\subsubsection{La concepción sustancialista subyacente a la lógica aristotélica}

La idea que se encuentra como soporte de la lógica aristotélica es la idea de predicación. Esta, a su vez, se basa en su concepción sustancialista de la realidad estructurada a partir de los conceptos de ousía (sustancia), accidente, género y especie. La ontología y lógica se encuentran, en Aristóteles, en una relación de dependencia. Así pues, la lógica tal y como la concebía el Estagirita estaba determinada por el marco ontológico en que aquella concepción quedaba encuadrada: una metafísica sustancialista. Este carácter metafísico exhibido por la concepción aristotélica de la lógica fue cuestionado. Pensemos, por ejemplo, en que, para Aristóteles, la lógica debía estar referida necesariamente al mundo, es decir, debía ser utilizada para describir la estructura de la realidad. Así, para el Estagirita, la proposición de que Todos los médicos son profesionales debe implicar que Existen médicos. Esto no ocurre en lógica moderna ya que esta es capaz de asumir que el antecedente de esta proposición universal afirmativa podría ser una función sin ejemplificaciones concretas, es decir, una proposición falsa. Por este motivo, resulta siendo limitada en lo tocante a la lógica cuantificacional de primer grado. Es decir, afirmar que todo médico es profesional no implica asumir que existen médicos. Este último rasgo es lo que troca en metafísica a la lógica, o sea, la relaciona a la estructura del mundo. Más bien, la lógica es una forma de hablar sobre el mundo, sobre cómo podría ser y no sobre cómo es. De este modo se entiende la lógica en la actualidad y es de este modo como ha podido progresar. Así, en el contexto de desarrollo de la lógica moderna aquella estructura dominante, ligada a una ontología sustancialista y a una concepción cualitativa del mundo hubo de ser modificada radicalmente. (Tejada, 2014)

Pues bien, la confusión que se genera como fruto del empleo de la estructura sujeto-predicado, propia de la silogística aristotélica es disipada por el capital aporte que Frege (1972) hace al ámbito de la investigación lógica a partir de la incorporación de las nociones de función y argumento. Aquella estructura lógica propia del pensar aristotélico al calcar el perfil gramatical del habla cotidiana no lograba aprehender apropiadamente la real relación que se establece entre los elementos que hacen las veces de sujeto y predicado en una proposición universal. Si se dice, José es médico, se ve que esta proposición ostenta una estructura conformada por un sujeto y un predicado; su negación, correctamente establecida, será José no es médico. Pero si se tiene, Todos los limeños son sudamericanos, al tipificar la estructura de esta proposición como lo hacía Aristóteles, es decir, como una estructura correspondiente a la forma sujeto-predicado, se podría creer, falsamente, que su negación habría de ser, Todos los limeños no son sudamericanos lo cual no es verdad, puesto que la proposición contradictoria de una proposición universal afirmativa es una proposición particular negativa. Y es así, porque la negación afecta en realidad a los predicados que conforman aquella proposición universal afirmativa, pues esta, en realidad, posee una forma distinta de aquella que, erradamente, parece contener un sujeto y un predicado. Esto queda claramente establecido luego de reformular dicha estructura. Al proceder así, aquella 
proposición universal afirmativa adopta la siguiente forma lógica: $(\forall \mathrm{x})(\mathrm{Lx} \rightarrow \mathrm{Sx})$ (es decir, Para todo $x$, si $x$ es limeño, entonces $x$ es sudamericano). A la luz de esta nueva interpretación, lo que se advierte es que un concepto -limeño- está subordinado a otro-sudamericano. Se nota, entonces, que no se trata de un sujeto y un predicado, sino de dos conceptos, uno de los cuales, en su condición de expresión predicativa (ser limeño) se predica de una variable cuantificada, y, a su vez, se subordina al otro concepto que en su calidad de expresión predicativa (ser sudamericano) se predica de una variable también cuantificada.

\subsection{Casos Especiales de Proposiciones}

El análisis de la lógica aristotélica lleva a cuestionar los llamados cuatro casos atípicos (Asociación Fondo de investigadores y editores, 2007). Enseguida se desarrollan y se hacen las observaciones.

1. Cuando el cuantificador no está explícito o es desconocido, entonces se interpreta el sentido de toda la expresión entera y se la considera como si fuera cualquiera de las proposiciones categóricas típicas ya conocidas.

2. Cuando el sujeto o el predicado de la proposición, o ambos, se encuentran negados, entonces, en la fórmula booleana, se les interpreta como complemento del término negado.

3. Si en una proposición categórica el cuantificador se encuentra negado, entonces al aplicársele la formula booleana la negación pasará a afectar la igualdad o la desigualdad.

4. Si en una proposición categórica universal (A, E) se encuentra que el verbo copulativo está negado, la negación funciona como si negara al cuantificador y se procede como en el caso anterior. Véase la Figura 4.

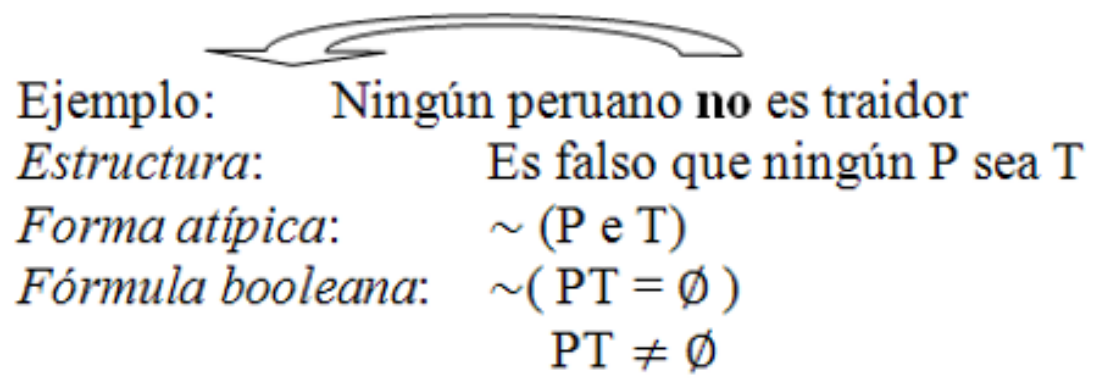

Diagrama de Venn:

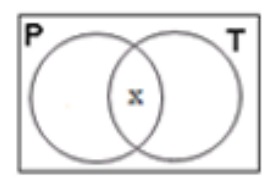

FIGURA 4

Análisis de una proposición categórica. Caso de la negación del verbo una proposición universal negativa Fuente: Elaboración propia

Este cuarto caso es problemático, pues el caso de Todo $x$ no es y se debe interpretar como Ningún x es y. Así, por ejemplo, Pérez (2006) considera que la E tiene la estructura de Todo $S$ no es $P$ y, en analogía, el caso de Ningún $x$ no es y se debe interpretar como Todos los $x$ son $y$. Esto se explica porque la SeP, que es una proposición universal negativa, equivale a Todo $x$ no es $y$. Según este cuarto caso, la proposición: Todos los aliancistas no son universitarios equivale a esta otra: Algunos aliancistas no son universitarios. Esto me parece ciertamente observable por una serie de razones de índole formal.

Por ejemplo, se asume que Todos los números no son impares (F). Según la regla antes mentada, dicho enunciado equivale a Algunos números no son impares (G). Sin embargo, la proposición $F$ es falsa, mientras que 
$\mathrm{G}$ es verdadera. Para que una proposición sea la equivalente de otra debe mantener su verdad o su falsedad, lo cual se ve no ocurre si se sigue la regla del caso.

En cambio, si se sigue la regla que afirma que Todo x no es y equivale a Ningún x es y se logra mantener el valor de verdad original. Así pues, cuando se dice que $F$, se afirma que: 1 no es impar $\wedge 2$ no es impar $\wedge 3$ no es impar $\wedge 4$ no es impar $\wedge 5$ no es impar $\wedge \ldots$

Como se sabe que en una conjunción basta que un componente sea falso para que todo sea falso, entonces al saber que 1 no es impar es falso, se asume que $\mathrm{F}$ es falso. Ahora bien, como se sabe que Ningún número es impar $(\mathrm{H})$ es falso, se puede pasar de $\mathrm{F}$ a $\mathrm{H}$ manteniendo el valor de verdad de la expresión original.

\subsection{Inferencias Inmediatas por Operación}

Las inferencias inmediatas por operación son aquellas en las que a partir de una proposición categórica cualquiera se infiere una nueva proposición categórica modificando los términos. Este tipo de inferencias difiere un poco de las inferencias inmediatas por oposición, pues la característica fundamental de estas últimas es que para poder desarrollarlas se deben tener exactamente los mismos términos, y en las inferencias por operación se trata de modificarlos. Las inferencias inmediatas por operación son un conjunto de 3 sencillas operaciones con las cuales se pueden modificar los términos de una proposición dada, conservando el valor de verdad, siempre y cuando este sea verdadero. Estas son la conversión, la obversión y la contraposición. Como se sabe los términos tienen tres características: su distribución, su ubicación y si son complementarios o no. Según estas características, los términos pueden modificarse de dos maneras diferentes: cambiando su ubicación en la proposición o cambiándolos por su complemento. Estos dos tipos de modificaciones dan lugar a las dos primeras inferencias inmediatas por operación, a las que se llama conversión y obversión.

\subsubsection{Conversión}

Son inferencias entre proposiciones de la misma calidad en las que se permuta (intercambia) el sujeto con el predicado. Hay dos tipos de conversión: la simple y la por accidente. En la conversión simple la letra se mantiene. Pero, en la conversión por accidente cambia la letra por su subalterna, (I y O no tienen subalterna sino subalternante).

-Conversiones simples I. S e P $\rightarrow$ P e S II. S i P $\rightarrow$ P i $S$

-Conversiones por accidente I. $S$ a $\mathrm{P} \rightarrow \mathrm{P}$ i $S$ II. $\mathrm{S}$ e $\mathrm{P} \rightarrow \mathrm{P}$ o $S$

${ }^{*}$ Las conversiones por accidente resultan inválidas de acuerdo a la lógica cuantificacional. En el primer caso, a partir de $(\forall x)(S x \rightarrow P x)$ no se puede deducir $(\exists x)(\operatorname{Px} \wedge S x)$ salvo que se acepte $(\exists x)$ Sx. En el segundo, de $(\forall \mathrm{x})\left(S_{\mathrm{x}} \rightarrow \sim \mathrm{Px}\right)$ no se puede deducir $(\exists \mathrm{x})\left(\mathrm{Px} \wedge \sim \mathrm{Sx}_{\mathrm{x}}\right.$ salvo que se acepte $(\exists \mathrm{x})$ Px.

\subsubsection{Obversión}

Son inferencias entre proposiciones de la misma cantidad, pero de diferente calidad. El orden de sujeto y predicado se respeta, pero el predicado de la conclusión aparece negado. La letra de la conversa de una cierta proposición será su contraria (o subcontraria) según el cuadro de Boecio.

I. $S$ a $\mathrm{P} \rightarrow \mathrm{S}$ e $\bar{p}$ II. $S$ e $\mathrm{P} \rightarrow \mathrm{S}$ a $\bar{p}$ III. $\mathrm{S}$ i $\mathrm{P} \rightarrow \mathrm{S}$ o $\bar{p}$ IV. $\mathrm{S}$ o $\mathrm{P} \mathrm{S}$ i $\bar{p}$ 


\subsubsection{Contraposición parcial}

Las contraposiciones son operaciones que dependen de la conversión y de la obversión. Existen dos tipos de contraposiciones: parciales y totales. Las contraposiciones parciales son las inferencias productos de la conversión de una obversión.

I. $S$ a $\mathrm{P} \rightarrow \bar{p}$ e S II. S a $\mathrm{P} \rightarrow \bar{p}$ o $S$ III. S e $\mathrm{P} \rightarrow \bar{p}$ i $S$ IV. $\mathrm{S}$ o $\mathrm{P} \rightarrow \bar{p}$ i $\mathrm{S}$

${ }^{*}$ La segunda contraposición parcial $(\mathrm{SaP} \rightarrow \bar{p} \mathrm{oS})$ es inválida para la lógica cuantificacional. Para que sea válida tiene que aceptarse $(\exists x) \sim$ Px. Igualmente, la tercera contraposición parcial también es inválida. Para que sea válida tiene que aceptarse $(\exists \mathrm{x}) \mathrm{S} \mathrm{x}$.

\subsubsection{Contraposición total}

Las contraposiciones totales (C. T.) son inferencias productos de la obversión de la conversión de una obversión, es decir, la obversión de una contraposición parcial. Ya que I no tiene contrapuesta parcial tampoco tendrá contrapuesta total pues esta nace solo cuando se le aplica la obversión a una contrapuesta parcial.

I. $S$ a $\mathrm{P} \rightarrow \bar{p}$ a $\bar{s}$ II. $S$ a $\mathrm{P} \rightarrow \bar{p}$ i $\bar{S}$ III. $S$ e $\mathrm{P} \rightarrow \bar{p}$ o $\bar{s}$ IV. $S$ o $\mathrm{P} \rightarrow \bar{p}$ o $\bar{s}$

${ }^{*}$ La segunda contraposición total $(\mathrm{S}$ a $\mathrm{P} \rightarrow \bar{p}$ i $\bar{S})$ es inválida para la lógica cuantificacional. Para que sea válida tiene que aceptarse $(\exists \mathrm{x}) \sim \operatorname{Px}$. De igual manera, la tercera contraposición total es inválida. Para que sea válida tiene que aceptarse $(\exists \mathrm{x}) \mathrm{Sx}$.

\subsection{Silogismo categórico}

Aristóteles define al silogismo como un

discurso en el que una vez concedidas ciertas premisas, se siguen, o concluyen, necesariamente otras proposiciones. Es decir, las mismas premisas producen la consecuencia y, por ello, no se requiere de ningún otro término adicional para hacer que la consecuencia sea necesaria (Aristóteles, 1995, p. 95).

En otras palabras, un silogismo es una estructura inferencial deductiva en la que se deriva una conclusión, de manera necesaria, a partir de dos premisas, las cuales poseen una estructura conformada por un sujeto y un predicado.

\subsubsection{Validez del silogismo por reglas aristotélicas}

La lógica aristotélica analiza la validez o invalidez de los silogismos aplicando las siguientes ocho reglas propuestas por el padre de la lógica antigua:

1. Reglas obvias:

R1. Todo silogismo debe contener únicamente tres términos (mayor, menor y medio).

R2. El término medio solo debe estar contenido en las premisas, nunca en la conclusión.

R3. La conclusión se construye con las características débiles de las premisas, entendiéndose como débil a la característica particular o negativa. Para reconocer lo débil, vea la Tabla 1. 
TABLA 1

Características de las proposiciones categóricas

\begin{tabular}{|llllll|}
\hline $\begin{array}{c}\text { Letra } \\
\text { tipica }\end{array}$ & $\begin{array}{c}\text { Forma } \\
\text { típica }\end{array}$ & Distribución & Calidad & Cantidad & LO DÉBIL \\
\hline A & SaP & S & Afirmativa & Universal & - \\
\hline E & SeP & S y P & Negativa & Universal & Negativa \\
\hline I & SiP & -- & Afirmativa & Particular & Particular \\
\hline & & & Negativa & Particular & $\begin{array}{l}\text { Negativa } \\
\text { particular }\end{array}$ \\
\hline
\end{tabular}

Fuente: Elaboración propia.

2. Reglas de términos:

R4. El término medio debe estar distribuido en, por lo menos, una de las premisas.

R5. Si en el silogismo válido hay un término distribuido en la conclusión, debe estar distribuido en su respectiva premisa.

3. Reglas de calidad:

R6. Si las dos premisas son afirmativas, no puede haber conclusión negativa. Un silogismo construido de esa forma es inválido.

R7. Si las dos premisas son negativas, nada se sigue. Un silogismo construido de esa forma es inválido.

4. Regla de cantidad:

R8. Si las dos premisas son particulares, nada se concluye. Un silogismo construido de esa forma es inválido.

\subsubsection{Las repercusiones de la clase vacía}

El concepto de clase vacía, es decir, que carece de elementos, fue introducido explícitamente en el Analysis de George Boole (1847), al tomar el cero del álgebra como símbolo de esta clase. Esto se le ocurrió al interpretar la expresión: Todos los $X$ son $Y$. Dado que todos los $\mathrm{X}$ que existen se encuentran en la clase $\mathrm{Y}$, es evidente que tomar del universo todos los $\mathrm{Y}$, y de estos todos los $\mathrm{X}$, es lo mismo que tomar del universo todos los $\mathrm{X}$. En términos formales: $\mathrm{x} y=\mathrm{x}$

Es decir, la intersección entre la clase de los x y la de los y se reduce a la clase de los x. Además, pasando a restar xy a ambos miembros de la ecuación y factorizando resulta: $0=\mathrm{x}-\mathrm{x} \mathrm{y}$

$0=\mathrm{x}(1-\mathrm{y})$

Lo cual se interpreta como que la intersección entre la clase de los x y el complemento de la clase de los y $((1-y)$ equivale a $)$ no existe, es decir, se reduce a la clase vacía. De esta manera, cuando Boole introduce el concepto de clase universal, representado por el símbolo 1 y entendiéndose como abarcando todas las clases pensables de objetos, bien existan realmente o no, obliga a aceptar sin fundamento el de clase vacía. El concepto de clase vacía condujo a plantear el problema de la validez de ciertas proposiciones de la silogística aristotélica. Schröder (1981, citado por Bochen 'ski, 1985) señaló que:

Desde el punto de vista de nuestra teoría tenemos que declarar incorrectos un cierto número de estos modos (silogísticos), entre los cuales (hay que incluir) en particular también todas las formas 'reducidas' (...), e. d., todas aquellas deducciones mediante las cuales, de premisas puramente universales, se deduce un juicio particular. Estas, consideradas más atentamente, aparecerán como entimemas que omiten tácitamente una premisa existencial: mas al punto en que esta se formula explícitamente, y se añade como complemento a las restantes premisas, es evidente que descansan sobre tres premisas, con lo cual dejan de ser 'simples' silogismos, e incluso de ser en absoluto 'silogismos' (p. 381)

La premisa ausente tiene la siguiente formulación de la siguiente manera: "Será concluyente la deducción, solo cuando a las citadas premisas se les añada a modo de otra premisa más (...), e. d., la suposición de que 
hay individuos de la clase del sujeto" (Schröder, 1981 citado por Bochen'ski, 1985, p. 382). Así pues, se logran rechazar dos reglas aristotélicas: 1) "Es de advertir, según esto: que una deducción por subalternación es inadmisible en Lógica exacta” (Schröder, 1981 citado por Bochen'ski, 1985, p. 382). Y, 2) "Es [...] de advertir, además: De las conversiones de la Lógica tradicional, únicamente la conversión pura es admisible en Lógica exacta (e. d. la conversio per accidens no [...])" (Schröder, 1981 citado por Bochen'ski, 1985, p. 382).

De acuerdo a Bochen' ski: "Los modos a que aquí se alude son estos: Darapti, Felapton, Bamalip, Fesapo y los cinco subalternos: Barbari, Celaront, Cesaro, Camestrop, Calemop”. (Bochen'ski, 1985, p. 382)

Esto origina que se rechace por incorrectas ciertas inferencias que en la lógica silogística tradicional se dan por correctas: Darapti, Felapton, Bamalip y Fesapo, entre otras. Para salvar la validez de estas inferencias (aparentemente correctas) se podría admitir que en el lenguaje cotidiano las afirmaciones universales tienen un cierto contenido existencial. La cuestión es, entonces, si en el lenguaje cotidiano el significado de las oraciones en cuestión incluye el mencionado contenido existencial. Sucede, pues, que las deducciones tradicionales suponen que hay un contenido metafísico que se relaciona con la existencia real del sujeto vinculado al predicado. Para dilucidar esto, es necesario distinguir entre las condiciones de verdad de una oración y los principios pragmáticos que rigen su uso.

\section{Discusión}

Como se ha expuesto, las reglas aristotélicas para determinar la validez de los silogismos ahora se presentará una crítica al respecto. Los silogismos categóricos de forma típica serán válidos si pasan exitosamente el examen de las ocho reglas del silogismo planteados por Aristóteles. De los 256 modos solamente son válidos 24 modos, a 19 de los cuales los lógicos medievales les dieron nombres nemotécnicos. Así, al modo AAA que es válido solo en la primera figura le llamaron BARBARA. A continuación, véase en la Tabla 2 los 24 modos válidos según la nemotecnia medieval:

TABLA 2

Los 24 modos válidos

\begin{tabular}{llll}
\hline Primera figura & $\begin{array}{l}\text { Segunda } \\
\text { figura }\end{array}$ & Tercera figura & Cuarta figura \\
\hline BARBARA & CESARE & DARAPTI & BAMALIP \\
\hline CELARENT & CAMESTRES & FELAPTON & CAMENES \\
\hline DARII & FESTINO & DATISI & DIMATIS \\
\hline FERIO & BAROCO & DISAMIS & FESAPO \\
\hline AAI & AEO & BOCARDO & FRESISON \\
\hline EAO & EAO & FERISON & AEO \\
\hline
\end{tabular}

Fuente: Rosales (1994, p. 155).

Pero, de los 24 silogismos válidos de acuerdo con las reglas de Aristóteles, solo 15 son lógicamente válidos a la luz de los métodos de la lógica moderna. Esto se puede ver en la Tabla 3: 
TABLA 3

Los 15 modos válidos

\begin{tabular}{|llll|}
\hline Primera figura & $\begin{array}{l}\text { Segunda } \\
\text { figura }\end{array}$ & Tercera figura & Cuarta figura \\
\hline $1-\mathrm{AAA}$ & $2-\mathrm{EAE}$ & $3-\mathrm{AII}$ & $4-\mathrm{AEE}$ \\
\hline $1-\mathrm{EAE}$ & $2-\mathrm{AEE}$ & $3-\mathrm{IAI}$ & 4-IAI \\
\hline $1-\mathrm{AII}$ & $2-\mathrm{EIO}$ & $3-\mathrm{OAO}$ & $4-\mathrm{EIO}$ \\
\hline $1-\mathrm{EIO}$ & $2-\mathrm{AOO}$ & $3-\mathrm{EIO}$ & \\
\hline
\end{tabular}

Fuente: García (2012, p. 149).

Como se sabe, la validez de un silogismo depende exclusivamente de su forma y es completamente independiente de su contenido. Así, cualquier silogismo de la forma 1-AAA es válido, sea cual fuere aquello de lo que trate, en virtud de su forma. Ahora bien, es de notar que los silogismos rechazados son 1-AAI, 1EAO, 2-AEO, 2-EAO, 3-AAI, 3-EAO, 4-AAI, 4-EAO, 4-AEO, es decir, nueve en total. Para que las reglas aristotélicas puedan aún ser de ayuda habría que considerar una novena regla. Si se observa bien lo que tienen en común dichos silogismos rechazados es que las premisas son universales mientras que la conclusión es particular. Así pues, se estipula la siguiente regla adicional a las anteriores ya mencionadas:

R.9. Si las premisas son universales, no puede deducirse una particular.

De todo lo anterior, puede colegirse que la lógica aristotélica que se exige en los temarios de exámenes de admisión debería ser revisada con base en la lógica cuantificacional de primer grado. Hay que tomar en cuenta que si se está propiciando un interés por conocer formas lógicas incorrectas entonces se está alentando un puro aprendizaje mecánico y memorístico. Y la universidad debería incentivar más bien el pensamiento crítico. Precisamente, este pensamiento crítico se logra con unas herramientas adecuadas, las cuales vienen dadas por la lógica cuantificacional de primer grado.

Como es sabido, existe cierta reticencia hacia la lógica por su formalidad ya que contiene mucha abstracción, la misma abstracción que Miró Quesada planteaba como aquello que origina el rechazo hacia la lógica por no permitir ni incentivar fácilmente la capacidad de poder entender dicho lenguaje por parte de los y las estudiantes. Es notable, pues, la importancia dada al tema del lenguaje vinculado con el pensamiento y la lógica. El lenguaje, dice Miró Quesada, es como el soporte del pensamiento, ya que sin él el pensar no podría alcanzar permanencia y objetividad. Y continúa: "estudiando el lenguaje se ve claramente la necesidad que se tiene de respetar las leyes lógicas y además de atender a la situación concreta en que las palabras son empleadas" (Miró, 1968, p. 218). Es necesario agregar que el lenguaje más adecuado a los intereses de la ciencia hoy por hoy es el lenguaje de la lógica cuantificacional de primer grado, la cual presupone la lógica proposicional y supera la lógica aristotélica en precisión y rigor.

De este modo, se coincide con Tejada (2014) al afirmar:

De manera semejante al modo en que se abandonó la vieja concepción geocéntrica del universo; así como la física aristotélica fue desplazada por la física experimental de Galileo; del mismo modo en que, más tarde, la mecánica newtoniana fue rebasada en su alcance por la teoría de la relatividad general de Einstein; en fin, así, como en el curso de la historia de la ciencia natural la humanidad ha asistido a la clausura de ciertas perspectivas y a la apertura de nuevos caminos, de modo parejo, hasta donde me es dado ver, bien podría hablarse, en los terrenos de la lógica, del ocaso de la silogística aristotélica oscurecida por el horizonte de la «nueva lógica. (p. 25)

Si las universidades están hechas mirando hacia el futuro, hacia el progreso y hacia la modernidad, entonces una de las cosas que podría hacer para representar esa actitud es exigir una lógica que no esté cargada de errores y que pertenezca a un anterior paradigma de razonamiento que ha sido superado en sus aspectos más básicos. Esta nueva lógica no sólo le permitirá ahondar en sus habilidades de abstracción y concreción de la información, sino que también le procurará la necesidad de establecer nexos con la matemática de una manera elemental. No se trata de ser extremistas y de pedir que se eliminen esos contenidos anteriores, pues estos 
también dotan de ciertas habilidades muy útiles al futuro ingresante. No se dice que una lógica sea mejor que otra. Este caso es análogo a lo que ocurre con las operaciones matemáticas. Es posible creer que lo que sucede es que solo se está exigiendo saber sumar y restar (lógica aristotélica); lo que se cuestiona es que solo se exija eso cuando se sabe que también es importante saber multiplicar y dividir (lógica cuantificacional de primer grado) y eso también se debería exigir. No se plantea que sea mejor una operación que otra, que sea mejor dividir que restar, por ejemplo. Solo se propone la idea de que deben ser complementarios. Específicamente, lo que se está sugiriendo es que también se les otorgue el mismo tiempo a la nueva lógica, la cual se presenta como un nuevo lenguaje que les permitirá conocer otros modos de razonar para poder así expandir sus intereses académicos. Si ahora se pide saber inglés en los temarios de exámenes de admisión, entonces el conocimiento de este lenguaje técnico-formal también debería figurar como exigencia.

\section{Conclusiones}

En esta investigación se ha arribado a las siguientes conclusiones:

1. Los temarios de las universidades de Lima-Perú actualmente reparten la materia de lógica entre los rubros de matemática y filosofía.Los temarios de las universidades de Lima-Perú actualmente reparten la materia de lógica entre los rubros de matemática y filosofía.

2. Las universidades no exigen el aprendizaje de la lógica cuantificacional de primer grado como requisito para medir el conocimiento de los ingresantes.

3. Según la lógica cuantificacional, en el cuadro de Boecio solo sobreviven relaciones entre las contradictorias, siendo tachadas por inválidas todas las demás relaciones.

4. Aristóteles presuponía que toda proposición universal conllevaba la existencia de al menos una cosa que tuviera la propiedad del sujeto.

5. Las correspondientes proposiciones universales de la lógica cuantificacional no presuponen que haya cosas que tengan la propiedad del sujeto.

6. La idea de predicación y la concepción sustancialista de la realidad fundamentan a la lógica aristotélica.

7. El caso de Todo $x$ no es $y$ se debe interpretar como Ningún $x$ es $y$.

8. El caso de Ningún x no es $y$ se debe interpretar como Todos los $x$ son $y$.

9. La lógica aristotélica analiza la validez o invalidez de los silogismos aplicando las ocho reglas propuestas por el Estagirita.

10. El concepto de clase vacía condujo a rechazar la validez de los siguientes silogismos: Darapti, Felapton, Bamalip y Fesapo.

11. Para que el sistema aristotélico sea coherente con la lógica de primer grado debe añadirse esta novena regla: Si las premisas son universales, no puede deducirse una particular.Para que el sistema aristotélico sea coherente con la lógica de primer grado debe añadirse esta novena regla: Si las premisas son universales, no puede deducirse una particular.

12. La lógica aristotélica que los temarios de las universidades de Lima-Perú exigen aprender no es del todo rigurosa pues contiene errores y limitaciones.

13. Las habilidades de abstracción y concreción de la información son propiciadas por la lógica cuantificacional de primer grado.

14. Es necesario exigir el aprendizaje de la lógica cuantificacional de primer grado a fin de que los ingresantes puedan contar con un mejor pensamiento crítico. 


\section{RECOMENDACIONES}

Sería interesante que se pudiera llevar a cabo algunos experimentos empíricos educativos con respecto a la enseñanza de la lógica en el nivel escolar de los colegios públicos de Lima-Perú. Esto con el fin de medir el rendimiento de las habilidades lógicas del alumnado para saber si aquella base con la que se cuenta es suficiente como para poder recibir contenidos propios de la lógica cuantificacional de primer orden. La idea es saber si el alumno percibiría como demasiado impactante este contenido o, más bien, si lo acogería con una adecuada recepción dentro de su universo cognitivo. Con esta información se podría tomar decisiones con mayor base y consideración. Pero esto ya sería materia de otra investigación.

\section{REFERENCIAS}

Arévalo, V. (2018). El examen de admisión a la Universidad Nacional de Ingeniería. (Tesis de Maestría). Universidad Peruana Cayetano Heredia (UPCH), Lima.

Aristóteles. (1995). Tratados de Lógica. Órganon II. Madrid: Gredos.

Asociación Fondo de investigadores y editores. (2007). Compendio académico de Psicología, Filosofía y Lógica. Lima: Lumbreras

Bocheński, I. M. (1985). Historia de la lógica formal. Madrid: Gredos.

Boole, G. (1847), The Mathematical Analysis of Logic. Cambridge: Macmillan.

Bieberach, C. (1971) Introducción a la filosofía y lógica práctica. Lima: Editorial Universo S. A.

Blasco, P. y Chico P. (s.f.) Filosofía y Lógica. Lima: Editorial Bruño.

Bretel, L (s.f.) Filosofía y lógica. Lima: Bruño y Centro de Proyección Cristiana.

Copi, I. (2001). Lógica simbólica. México: CECSA.

Frege, G. (1972). Conceptografía. Los fundamentos de la Aritmética. México: UNAM.

García, Ó. y Palacios, R. (1998). Lógica matemática como disciplina curricular. Lima: Artes Impresos.

García, Ó. (2012). Elementos de lógica. Lima: Visual Press.

García, S. y Rosales D. (1984) Filosofía y Lógica. Lima: Amaru Editores S. A. y Editorial Mantaro.

Garduño, F. (2000). Los exámenes de admisión y la selección a la universidad pública Łrazón pedagógica o racionalidad técnica? Revista del Centro de Investigación Universidad La Salle, 4(14), 11-18.

Gildomero, L y García, Ó. (1984). Filosofía y lógica. Lima: Grafotécnica.

Gutiérrez, J. y Saldaña, L. (s.f.) Introducción a la filosofía y lógica. Lima: Editorial Arica S. A.

Kneale, W. y Kneale, M. (1980). El desarrollo de la lógica. Madrid: Tecnos.

Manzano, M. y Huertas, A. (2004). Lógica para principiantes. Madrid: Alianza Editorial.

Miró, F. (1968) Lógica. Lima: [sin editorial]

Núñez, J. (1984) Filosofía y lógica. Lima: Editorial Artemisa

Peñaloza, W. (1967) Introducción a la Filosofía y Lógica. Lima: Editorial Colegio Militar Leoncio Prado.

Pérez, M. (2006). Lógica clásica y argumentación cotidiana. Bogotá: Pontificia Universidad Javeriana.

Piscoya, L. (1978) Filosofía y lógica. Lima: Editorial Imprenta D. E. S. A.

Ponce, C. y Escurra, M. (2008). Estudio psicométrico sobre el examen de admisión 2008-i a la Universidad Nacional Mayor de San Marcos. Revista IIPSI, Facultad de Psicologia, 11 (1), 137-152.

Quesada, D. (2005). Lógica clásica de primer orden. En C. Alchourrón (Coord.), Lógica. (pp. 71-104). Madrid: Trotta.

Redmond, W. (1999). Lógica simbólica para todos. México: Universidad Veracruzana.

Rosales, D. (1994). Introducción a la lógica. Lima: Amaru.

Salazar, A. y Miró, F. (1978) Introducción a la Filosofía y Lógica. Lima: Editorial Universo S. A. 
Rafael Félix Mora Ramírez. Razones por las cuales la lógica cuantificacional de primer grado debe ...

Tejada, J. (2014). Un cambio de paradigma: de la silogística aristotélica a la "nueva” lógica”. Tesis, 8(7), 9-26.

Trilce. (2005) Lógica / Psicología. Lima: [sin editorial]

Universidad Nacional de Barranca (UNAB) (2018). Temario para los Exámenes de Admisión. Recuperado de https:// bit.ly/2kkIHy5

Universidad Nacional del Callao (UNAC) (2019). Temario del examen de admisión. Recuperado de http://admisio n.unac.edu.pe/temario.aspx

Universidad Nacional de Cañete (UNDC) (2018). Temario del Examen de Admisión 2018. Recuperado de http://u ndc.edu.pe/portal/wp-content/uploads/2016/10/TEMARIO_2018.pdf

Universidad de Educación Enrique Guzmán y Valle (UNE) (2019). Temario. Recuperado de https://bit.ly/2lGc8dT

Universidad Nacional Federico Villareal (UNFV) (2019). Temario. Recuperado de https://bit.ly/2Xsll8c

Universidad Nacional de Ingeniería (UNI) (2019). Asignaturas para el examen de admisión ordinario. Recuperado de https://bit.ly/2lUkRt8

Universidad Nacional Mayor de San Marcos (UNMSM) (2013). Biografía de Francisco Miró Quesada Cantuarias. Recuperado de http://www.unmsm.edu.pe/ilustres/biografia/47

Universidad Nacional José Faustino Sánchez Carrión (UNJFSC) (2017). Contenidos temáticos del prospecto de admisión 2018-I. Recuperado de http://webcache.googleusercontent.com/search?q=cache:DKALwwiJPHIJ:w ww.unjfsc.edu.pe/archivos/admision/TEMARIO/7a6605913446e5f4d0428b54f28c9f6d76221617.pdf+\&c $\mathrm{d}=2 \& \mathrm{hl}=\mathrm{es}-419 \& \mathrm{ct}=\mathrm{clnk} \& \mathrm{gl}=\mathrm{pe}$

Universidad Nacional Tecnológica de Lima Sur (UNTELS) (2017). Temario. Examen de Admisión. Recuperado de http://www.untels.edu.pe/documentos/permanente/admisionTemario2017_2.pdf

CC BY-NC-ND 